\title{
Dietary associations of fathers and their children between the ages of 20 months and 5 years
}

\author{
Adam D Walsh ${ }^{1, *}$, Adrian J Cameron ${ }^{2,3}$, David Crawford ${ }^{1}$, Kylie D Hesketh ${ }^{1}$ \\ and Karen J Campbell ${ }^{1}$ \\ ${ }^{1}$ Centre for Physical Activity and Nutrition Research, School of Exercise and Nutrition Sciences, Deakin University, \\ 221 Burwood Highway, Burwood, VIC 3125, Australia: ${ }^{2}$ School of Health and Social Development, Deakin \\ University, Burwood, Victoria, Australia: ${ }^{3} \mathrm{WHO}$ Collaborating Centre for Obesity Prevention, Deakin University, \\ Burwood, Victoria, Australia
}

Submitted 28 October 2015: Final revision received 14 March 2016: Accepted 16 March 2016: First published online 18 April 2016

\begin{abstract}
Objective: To examine associations between dietary intakes of fathers and their children at child age 20 months, 3.5 years and 5 years, and to determine if fathers' intake predicts change in children's intake between 20 months and 3.5 and 5 years of age.

Design: The diets of fathers and their first-born children participating in the longitudinal Melbourne Infant Feeding Activity and Nutrition Trial (InFANT) Program were assessed using FFQ and three $24 \mathrm{~h}$ recalls, respectively.

Setting: Sixty-two pre-existing first-time parent groups were selected from fourteen local government areas within a $60 \mathrm{~km}$ radius of Deakin University Burwood, Victoria, Australia.

Subjects: Fathers and their first-born children at 20 months ( $n$ 317), 3.5 years $(n$ 214) and 5 years of age ( $n$ 208).

Results: Positive associations were found between fathers' and children's intakes of fruit and sweet snacks at 20 months $(P=0 \cdot 001)$ and 5 years of age $(P=0 \cdot 012)$. Fathers' intake at child age 20 months was associated with change in children's intake for fruit, sweet snacks and sugar-sweetened beverages between child age 20 months and 3.5 years, and for sweet snacks and sugar-sweetened beverages between child age 20 months and 5 years (all $P<0.05$ ). After adjustment for maternal intake, fathers' intake of sweet snacks remained a predictor of change in children's sweet snack intake between 20 months and 3.5 years of age $(P=0.03)$. Conclusions: Associations between the dietary intakes of fathers and their children commence at a young age and continue through early childhood. Fathers should be included in future interventions aimed at improving children's diets.
\end{abstract}

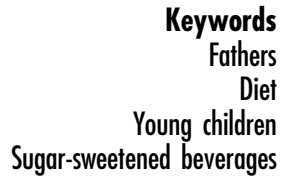

The dietary intakes of many young children are considered suboptimal, with low fruit and vegetable intakes and high intakes of nutrient-poor, energy-dense foods ${ }^{(1,2)}$. There is evidence that suggests this is the case even in children under the age of 5 years $^{(3,4)}$. Accumulating evidence indicates that poor dietary behaviours of young children often lead to overweight and obesity in later childhood and have adverse health consequences in adolescence and adult life ${ }^{(5)}$. Early childhood is a period when children learn about food and when their dietary patterns and preferences are formed ${ }^{(6-9)}$. Consequently this period has a strong influence on lifetime dietary intake ${ }^{(10-12)}$. While the influence of parents on young children's diets is considered pivotal, few studies investigating parent-child dietary intakes have been undertaken in children under the age of 5 years ${ }^{(13)}$. Furthermore, research in this area is heavily focused on maternal influences and rarely considers the role of fathers ${ }^{(14-16)}$.

A recent systematic review and meta-analysis by Wang and colleagues on the similarities between the diets of children and their parents found that only one-quarter of the twenty-four included papers contained father-specific analyses $^{(13)}$. Of those, only one included children under the age of 5 years; that by Beydoun and Wang, who reported in a US sample of 1473 households that fruit intakes were correlated between parents and their 2-10-year-old children ${ }^{(17)}$. Similarly, Rasmussen and colleagues noted that just eleven of ninety-eight papers included in their review of the determinants of children's and adolescents' fruit and vegetable consumption considered fathers' fruit intake. All eleven papers reported results for both parents combined, with no father-specific 
analyses conducted, thus limiting the ability to fully assess any paternal influences separately ${ }^{(15)}$.

Among the few studies pertaining to the relationships between children's and fathers' diets, Harris and Ramsey reported positive associations between African-American fathers' (including stepfathers and grandfathers) and their children's (3-13 years) intakes of fruits, vegetables and sweetened beverages ${ }^{(18)}$. Additionally, Robinson and colleagues reported positive correlations between the dietary intakes of fathers and children for fruit and grains ${ }^{(19)}$, while Hall and colleagues reported moderate to strong positive correlations between the dietary intakes of fathers and children for fruit, cookies and potato chips ${ }^{(20)}$. Both the Robinson and Hall studies were conducted among children of primary school age and in all the aforementioned studies the relationships reported did not adjust for maternal dietary intakes.

Although limited in number and scope, these studies collectively suggest that fathers' eating behaviours can influence their children's eating behaviours. Whether the diets of fathers and their children are independent of maternal influences is unknown. To address this evidence gap, the present study aimed to investigate the crosssectional associations between the dietary intakes of fathers and their children at child age of 20 months, 3.5 years and 5 years. It also investigated whether fathers' dietary intake is a predictor of the change in children's dietary intakes between 20 months and 3.5 and 5 years of age.

\section{Materials and methods}

\section{Study design and sample}

The Melbourne Infant Feeding Activity and Nutrition Trial (InFANT) Program was a cluster-randomized controlled trial undertaken within pre-existing first-time parent groups and has been described in detail elsewhere ${ }^{(21,22)}$. Using a two-stage random sampling design, sixty-two firsttime parent groups were selected from fourteen local government areas (across areas of all socio-economic position) within a $60 \mathrm{~km}$ radius of the research centre (Deakin University in Burwood, Victoria, Australia). Groups that consented to participate were randomly allocated to either the intervention or control arm. Inclusion criteria were a minimum of eight parents in the groups consenting to participate (or six parents in groups situated in areas of low socio-economic position) and English literacy.

Exclusion criteria for the study included not first-time parents ( $n$ 14), single-parent families ( $n$ 8), father as main caregiver ( $n$ 1), same-sex couple $(n 1)$ and families where fathers did not complete the baseline questionnaire ( $n$ 58). The sample available at baseline consisted of 460 fathers. Follow-up dietary data were missing for 143 to 252 fathers depending on the time point considered, thus the final sample consisted of 317 fathers at child age 20 months, 214 fathers at child age 3.5 years and 208 fathers at child age 5 years. To minimize the effect of missing data, analyses were conducted on the available sample at each time point.

The Deakin University Human Research Ethics Committee and the Victorian Government Department of Human Services, Office for Children, Research Coordinating Committee approved the Melbourne InFANT Program. All participants provided informed written consent.

\section{Measures}

Fathers' and mothers' dietary data were collected at baseline (child age 3 months) and at child age approximately 20 months, 3.5 years and 5 years using the previously validated ${ }^{(23)}$ Cancer Council Victoria FFQ. This is an updated version of the semi-quantitative FFQ developed specifically for the Melbourne Collaborative Cohort Study ${ }^{(24)}$. Fathers and mothers were asked independently to indicate on average how often they had consumed ninety-eight food items over the preceding 12 months, selecting one of ten response options ranging from 'never' to 'three or more times per day'. An additional question was included in the FFQ relating to the amount of diet and non-diet soft drinks consumed (glasses/d). These data were then converted into daily frequencies according the Cancer Council Victoria protocol. Demographic and socio-economic variables included fathers' age, country of birth, marital status, employment status, education level and main language spoken at home. Self-reported weight and height data were collected, with BMI calculated as [weight $(\mathrm{kg})] /[\text { height }(\mathrm{m})]^{2}$.

The dietary intakes of participating children were assessed by trained nutritionists over two or three non-consecutive days including one weekend day when children were approximately 20 months, 3.5 years and 5 years of age; three days of data were available for $97 \%$ of the study sample. This was performed through a telephone-administered multi-pass $24 \mathrm{~h}$ recall with the primary caregiver ${ }^{(25,26)}$. To assist in the assessment of foods and drinks considered difficult to quantify, purposedesigned booklets were provided to parents. The booklets included examples of measures and photographs of common portion sizes adapted to the child's age. Images of cups, spoons, bowls and drink containers were included in the booklets and were used with permission from the food model booklet produced for the 2007 Australian Children's Nutrition and Physical Activity Survey ${ }^{(27)}$. Dietary outcome variables assessed here were those reported in the primary outcome paper for the present study $^{(22)}$. These included the average daily intake (in $\mathrm{g} / \mathrm{d}$ for children and servings/d for fathers and mothers) of fruit (excluding juice), vegetables, non-core sweet snacks (e.g. chocolate, candy, cakes), non-core savoury snacks (e.g. potato chips, savoury biscuits), takeaway foods 
(reported as occasions/d for fathers and mothers), juices and sugar-sweetened beverages (SSB) ${ }^{(22)}$.

\section{Statistical analyses}

Linear regression analyses were used to assess crosssectional associations between children's and fathers' fruit, vegetable, non-core snack, juice and SSB intakes at child age 20 months, 3.5 years and 5 years. Linear regression was also used to examine the associations between fathers' intake at child age 20 months and change in child intake between 20 months and both 3.5 and 5 years of age. These models included child intake at age 20 months as a covariate in order to model the change ${ }^{(28)}$. As there were no differences in the dietary intakes of fathers between the intervention and control groups ${ }^{(29)}$, data from both groups were pooled at each time point. Further linear regression analyses of the change in mean intakes of fathers' diets indicated that fathers' intakes remained unchanged over time $(P>0 \cdot 05)$. Primary analyses were adjusted for intervention status and clustering by first-time parent group, with additional analyses also adjusted for maternal dietary intake. Collinearity between mothers' and fathers' dietary intakes was assessed by calculating the variance inflation factor using the Stata command estat vif. Demographic variables were compared between responders (at child age 20 months) and non-responders (at child age 5 years) using $t$ tests and $\chi^{2}$ analyses where appropriate. The significance level was set at $5 \%$. Analyses were conducted using the statistical software package Stata release 12 .

\section{Results}

Demographic characteristics for fathers participating in the present study at each time point are presented in Table 1. Mean paternal age was 35.7 years at child age 20 months increasing to 38.9 years at child age 5 years. Mean paternal
BMI decreased from $27.9 \mathrm{~kg} / \mathrm{m}^{2}$ at child age 20 months to $27 \cdot 1 \mathrm{~kg} / \mathrm{m}^{2}$ at child age 5 years. English was the main language spoken at home with the majority of the sample born in Australia. At child age 20 months, 55.9\% of fathers were non-university educated, which decreased to $45.7 \%$ at child age 5 years. The demographic characteristics of the fathers lost to follow-up at child age 5 years were not significantly different from those of fathers retained in the study other than for country of birth. A greater percentage of Australian-born participants were lost to follow-up between child age 20 months and 5 years (46\%v. 32\%, $P=0.03$ ). Table 2 presents fathers' and children's dietary intakes.

In cross-sectional analyses, positive associations were found between fathers and children for fruit and sweet snack intakes at 20 months and 5 years of age, with the strength of the association for both variables increasing between both these time points (Table 3). The strength of the association also increased markedly between child age 20 months and 5 years for intake of vegetables, SSB and juices (Table 3). Following additional adjustment for maternal intake, only the observed associations for fruit and sweet snack intakes at child age 20 months remained positive (Table 3). In further analyses stratified by child sex, the only association observed was between fathers and 20-month-old girls for fruit (results not shown). Collinearity between maternal and paternal intakes for fruit and sweet snack intakes was insignificant with a variance inflation factor of 1.09 and 1.08 , respectively ${ }^{(30)}$. The mean variance inflation factor for all variables in each model was 1.06.

As fathers' intakes remained unchanged over time, fathers' intakes at child age 20 months were used as a potential predictor for change in child intake at child age 3.5 years and 5 years. Child intake at age 20 months was included in the model in order to model the change (Table 4). Fathers' intake at child age 20 months was predictive of the increase in children's intake between 20 months and 3.5 years of age for fruit, SSB and sweet

Table 1 Fathers' characteristics at child age 20 months, 3.5 years and 5 years, Melbourne Infant Feeding Activity and Nutrition Trial (InFANT) Program

\begin{tabular}{|c|c|c|c|}
\hline \multirow[b]{2}{*}{ Fathers' characteristic } & \multicolumn{3}{|c|}{ Child age } \\
\hline & 20 months $(n 317)^{\star}$ & 3.5 years $(n 214)^{\star}$ & 5 years $(n 208)^{\star}$ \\
\hline Age (years), mean & $35 \cdot 7$ & $37 \cdot 6$ & 38.9 \\
\hline SD & 4.9 & 4.8 & 4.5 \\
\hline BMI $\left(\mathrm{kg} / \mathrm{m}^{2}\right)$, mean & $27 \cdot 9$ & 27.4 & $27 \cdot 1$ \\
\hline $\mathrm{SD}$ & 5.4 & 4.3 & 4.0 \\
\hline \multicolumn{4}{|l|}{ BMl category (\%) } \\
\hline Healthy weight $\left(\leq 24.99 \mathrm{~kg} / \mathrm{m}^{2}\right)$ & $32 \cdot 3$ & $32 \cdot 7$ & $30 \cdot 9$ \\
\hline Overweight $\left(>24.99-29.99 \mathrm{~kg} / \mathrm{m}^{2}\right)$ & 43.4 & $48 \cdot 8$ & 48.5 \\
\hline Obese $\left(\geq 30.00 \mathrm{~kg} / \mathrm{m}^{2}\right)$ & $24 \cdot 3$ & 18.5 & $20 \cdot 6$ \\
\hline \multicolumn{4}{|l|}{ Education level (\%) } \\
\hline University & $44 \cdot 1$ & 51.4 & $54 \cdot 3$ \\
\hline \multicolumn{4}{|l|}{ Country of birth (\%) } \\
\hline Australia & 78.5 & $75 \cdot 7$ & 74.5 \\
\hline \multicolumn{4}{|l|}{ Language spoken at home (\%) } \\
\hline English & $97 \cdot 4$ & $97 \cdot 6$ & $97 \cdot 0$ \\
\hline
\end{tabular}

${ }^{*} n$ for each time point is for dietary intake data. 
Table 2 Fathers' and children's intakes at child age 20 months, 3.5 years and 5 years, Melbourne Infant Feeding Activity and Nutrition Trial (InFANT) Program

\begin{tabular}{|c|c|c|c|c|c|c|}
\hline \multirow[b]{3}{*}{ Food group } & \multicolumn{6}{|c|}{ Child age } \\
\hline & \multicolumn{2}{|c|}{20 months ( $n$ 317) } & \multicolumn{2}{|c|}{3.5 years $(n 214)$} & \multicolumn{2}{|c|}{5 years $(n 208)$} \\
\hline & Mean & SD & Mean & SD & Mean & SD \\
\hline \multicolumn{7}{|l|}{ Father (servings/d)† } \\
\hline Fruits & 3.5 & $1 \cdot 2$ & $3 \cdot 4$ & $1 \cdot 2$ & 3.6 & 1.2 \\
\hline Vegetables & 4.4 & 1.2 & 4.4 & 1.2 & 4.4 & 1.2 \\
\hline SSB (excl. juices) & 0.4 & 0.7 & 0.5 & $1 \cdot 1$ & 0.3 & 0.6 \\
\hline Juices & 0.4 & 0.5 & 0.4 & 0.5 & 0.3 & 0.4 \\
\hline Sweet snacks & 1.0 & 0.8 & $1 \cdot 1$ & 0.9 & 1.0 & 0.9 \\
\hline Savoury snacks & 0.7 & 0.4 & 0.3 & 0.3 & 0.7 & 0.4 \\
\hline Takeaway foods* & $7 \cdot 9$ & $2 \cdot 1$ & $8 \cdot 1$ & $2 \cdot 0$ & 7.8 & 1.9 \\
\hline \multicolumn{7}{|l|}{ Child $(g / d)$} \\
\hline Fruits & 163.6 & 88.9 & $206 \cdot 4$ & $114 \cdot 8$ & $207 \cdot 8$ & 112.9 \\
\hline Vegetables & 99.1 & 68.2 & 98.6 & 79.5 & $126 \cdot 8$ & 92.4 \\
\hline SSB (excl. juices) & 3.9 & 31.0 & 19.7 & $60 \cdot 1$ & 23.5 & $51 \cdot 7$ \\
\hline Juices & $9 \cdot 3$ & 29.9 & $32 \cdot 8$ & 69.0 & 39.6 & $76 \cdot 3$ \\
\hline Sweet snacks & $12 \cdot 8$ & 14.7 & $42 \cdot 3$ & $33 \cdot 1$ & $45 \cdot 2$ & $35 \cdot 2$ \\
\hline Savoury snacks & 4.9 & 8.6 & $26 \cdot 0$ & 28.5 & 32.4 & 28.4 \\
\hline Takeaway foods & 4.6 & $12 \cdot 7$ & 6.5 & $15 \cdot 5$ & $7 \cdot 8$ & $19 \cdot 8$ \\
\hline
\end{tabular}

SSB, sugar-sweetened beverages.

*Takeaway foods measured in occasions/d (not servings/d) for fathers.

tChange in mean intake of father unchanged from 20 months to 5 years $(P>0.05)$.

Table 3 Cross-sectional associations between fathers' and children's dietary intakes* at child age 20 months, 3.5 and 5 years, unadjusted $\dagger$ and adjusted for maternal intakeł, Melbourne Infant Feeding Activity and Nutrition Trial (InFANT) Program

\begin{tabular}{|c|c|c|c|c|c|c|c|c|c|c|c|c|}
\hline \multirow[b]{3}{*}{ Food group } & \multicolumn{4}{|c|}{20 months } & \multicolumn{4}{|c|}{3.5 years } & \multicolumn{4}{|c|}{5 years } \\
\hline & \multicolumn{2}{|c|}{ Unadjusted $\dagger$} & \multicolumn{2}{|c|}{ Adjusted $\ddagger$} & \multicolumn{2}{|c|}{ Unadjusted $†$} & \multicolumn{2}{|c|}{ Adjusted $\ddagger$} & \multicolumn{2}{|c|}{ Unadjusted $†$} & \multicolumn{2}{|c|}{ Adjusted $\ddagger$} \\
\hline & $\beta$ & $95 \% \mathrm{Cl}$ & $\beta$ & $95 \% \mathrm{Cl}$ & $\beta$ & $95 \% \mathrm{Cl}$ & $\beta$ & $95 \% \mathrm{Cl}$ & $\beta$ & $95 \% \mathrm{Cl}$ & $\beta$ & $95 \% \mathrm{Cl}$ \\
\hline Fruits & 11.5 & $4 \cdot 7,18 \cdot 2$ & $9 \cdot 7$ & $2 \cdot 6,16 \cdot 7$ & 11.8 & $-1 \cdot 3,24 \cdot 9$ & $6 \cdot 8$ & $-6 \cdot 7,20 \cdot 3$ & $21 \cdot 4$ & $4.9,37.9$ & $12 \cdot 2$ & $-3 \cdot 6,27 \cdot 9$ \\
\hline Vegetables & 4.9 & $-0.9,10.7$ & 3.9 & $-1 \cdot 2,9 \cdot 2$ & -0.5 & $-11.5,10.4$ & $-3 \cdot 0$ & $-13.5,7.4$ & $12 \cdot 1$ & $-0.5,24.6$ & $4 \cdot 6$ & $-7 \cdot 5,16 \cdot 7$ \\
\hline SSB (excl. juices) & 1.4 & $-2.9,5.9$ & 1.3 & $-3.2,5.9$ & 4.8 & $-7 \cdot 0,16 \cdot 7$ & 4.4 & $-6 \cdot 4,15 \cdot 3$ & 13.7 & $-2.5,30.0$ & 8.0 & $-3.8,19.9$ \\
\hline Juices & -1.9 & $-6 \cdot 0,2 \cdot 2$ & $-2 \cdot 2$ & $-6 \cdot 4,1.9$ & 9.2 & $-9 \cdot 7,28.2$ & -0.6 & $-24 \cdot 5,23 \cdot 3$ & 21.9 & $-2 \cdot 7,46 \cdot 7$ & 3.2 & $-23 \cdot 1,29 \cdot 6$ \\
\hline Sweet snacks & 1.8 & $0.1,3.4$ & $1 \cdot 8$ & $0.04,3.6$ & 1.7 & $-3 \cdot 2,6 \cdot 8$ & -0.2 & $-5 \cdot 3,4 \cdot 9$ & $5 \cdot 3$ & $1.7,8.9$ & $3 \cdot 1$ & $-0.7,6.9$ \\
\hline Savoury snacks & -0.1 & $-2 \cdot 3,2 \cdot 0$ & 0.1 & $-2 \cdot 1,2 \cdot 4$ & $9 \cdot 1$ & $-3 \cdot 2,21 \cdot 4$ & $10 \cdot 1$ & $-2 \cdot 9,23 \cdot 2$ & $-1 \cdot 8$ & $-9.4,5.7$ & -0.9 & $-8.7,6.9$ \\
\hline Takeaway foods§ & 0.6 & $-0.02,1.3$ & 0.6 & $-0.04,1.3$ & 0.01 & $-0.9,1.0$ & -0.3 & $-1.4,0.8$ & 0.2 & $-0.7,1.3$ & 0.5 & $-0.5,1.5$ \\
\hline
\end{tabular}

SSB, sugar-sweetened beverages.

*Intake was measured in $\mathrm{g} / \mathrm{d}$ or $\mathrm{ml} / \mathrm{d}$ for children and servings/d for fathers.

†Unadjusted analysis did adjust for intervention status and clustering.

$\ddagger$ Adjusted analysis indicates additional adjustment for maternal intake.

$\S$ Takeaway foods measured in occasions/d (not servings/d) for fathers.

snacks. Fathers' intake at child age 20 months was also predictive of an increase in children's intake between 20 months and 5 years of age for SSB and sweet snacks. These associations were only mildly attenuated after adjustment for mothers' intake (Table 4). The relationship between fathers' intake and increase in child intake of vegetables and juices (but not fruit) was stronger at 5 years than at 3.5 years. No evidence of any association between fathers' intake and change in children's intake of savoury snacks and takeaway foods was observed at any time point.

\section{Discussion}

The current findings suggest that fathers' diets are associated with the early-life development of children's diets.
Our observation of cross-sectional associations between fathers' and children's fruit intakes at 20 months and 5 years of age supports findings from previous studies in older children. For example, Robinson and colleagues reported moderate positive correlations for fruit intake between Australian fathers and their children aged 8-12 years ${ }^{(19)}$, while Beydoun and Wang reported children's fruit intake was associated with parental fruit intake for both age subgroups analysed in their study of US families (2-10 years and $11-18$ years $)^{(17)}$. The associations between fathers' and children's fruit and sweet snack intakes were maintained at child age 20 months even when adjusting for maternal intake. Associations between the dietary intakes of both mother/ father and mother/child pairs have been demonstrated previously ${ }^{(15,19,31,32)}$, and so the maintenance of these 
Table 4 Associations between fathers' dietary intake at 20 months and change in children's dietary intakes* between child age 20 months and both 3.5 years and 5 yearst, Melbourne Infant Feeding Activity and Nutrition Trial (InFANT) Program

\begin{tabular}{|c|c|c|c|c|c|c|c|c|}
\hline \multirow[b]{2}{*}{ Food group } & \multicolumn{2}{|c|}{$\begin{array}{l}\text { Change between } 20 \text { months } \\
\text { and } 3.5 \text { years }\end{array}$} & \multicolumn{2}{|c|}{$\begin{array}{l}\text { When adjusted for } \\
\text { maternal intake }\end{array}$} & \multicolumn{2}{|c|}{$\begin{array}{l}\text { Change between } 20 \text { months } \\
\text { and } 5 \text { years }\end{array}$} & \multicolumn{2}{|c|}{$\begin{array}{l}\text { When adjusted for } \\
\text { maternal intake }\end{array}$} \\
\hline & $\beta$ & $95 \% \mathrm{Cl}$ & $\beta$ & $95 \% \mathrm{Cl}$ & $\beta$ & $95 \% \mathrm{Cl}$ & $\beta$ & $95 \% \mathrm{Cl}$ \\
\hline Fruits & $13 \cdot 3$ & $1 \cdot 0,25 \cdot 6$ & $5 \cdot 7$ & $-6 \cdot 4,17 \cdot 8$ & $6 \cdot 1$ & $-3 \cdot 8,16 \cdot 2$ & $2 \cdot 2$ & $-7 \cdot 9,12 \cdot 4$ \\
\hline Vegetables & 4.0 & $-1.9,10.0$ & 0.5 & $-5 \cdot 6,6 \cdot 5$ & $9 \cdot 7$ & $-1 \cdot 6,21.1$ & $5 \cdot 3$ & $-8.3,18.9$ \\
\hline SSB (excl. juices) & 29.5 & $0 \cdot 1,58 \cdot 8$ & $25 \cdot 3$ & $-8 \cdot 3,59 \cdot 0$ & $43 \cdot 7$ & $2 \cdot 9,84 \cdot 4$ & 39.1 & $-6 \cdot 1,84.5$ \\
\hline Juices & $-5 \cdot 3$ & $-21 \cdot 2,10 \cdot 6$ & $-7 \cdot 6$ & $-25.3,9.9$ & 20.4 & $-3 \cdot 3,44 \cdot 1$ & 13.5 & $-12 \cdot 8,40 \cdot 0$ \\
\hline Sweet snacks & $4 \cdot 3$ & $1 \cdot 2,7 \cdot 4$ & 4.5 & $1.3,7 \cdot 6$ & 3.5 & $0.4,6.7$ & 2.9 & $-0.4,6.3$ \\
\hline Savoury snacks & -3.0 & $-6 \cdot 0,0.0$ & $-3 \cdot 1$ & $-6.5,0.3$ & $-2 \cdot 3$ & $-6 \cdot 3,1 \cdot 6$ & $-2 \cdot 1$ & $-6 \cdot 2,1 \cdot 8$ \\
\hline Takeaway foods $\ddagger$ & 1.0 & $-0.9,2.9$ & 0.7 & $-1.4,2 \cdot 8$ & 1.3 & $-0.3,2.9$ & 0.8 & $-0.8,2.5$ \\
\hline
\end{tabular}

SSB, sugar-sweetened beverages.

*Intake was measured in $\mathrm{g} / \mathrm{d}$ or $\mathrm{ml} / \mathrm{d}$ for children and servings/d for fathers.

†All variables adjusted for intervention status, clustering and child intake at 20 months.

$\ddagger$ Takeaway foods measured in occasions/d (not servings/d) for fathers.

associations independent of maternal intake has important implications for the design and delivery of future family-based dietary interventions. Possible mechanisms by which fathers influence the dietary intakes of young children may be role modelling ${ }^{(9,33)}$ or food availability $^{(15,34)}$; however, these mechanisms have been studied primarily in the context of maternal influences in older children, with more research required in the context of paternal influences in young children.

When considering fathers' fruit intake at child age 20 months as a predictor of the change in child fruit intake, our observation that it was associated with change in child intake between 20 months and 3.5 years of age adds to the current body of literature regarding the influence of fathers on children's dietary behaviours. Combined with the results from both the Robinson and Beydoun studies, our results indicate that the association between fathers' and children's fruit intake commences in early life. This association in very early childhood may also be predictive of the change in fruit intake throughout the pre-school years.

The observation that fathers' SSB intake at child age 20 months influences change in children's SSB intake between the age of 20 months and both 3.5 years and 5 years is important given that early-life consumption of SSB has been shown to be a strong predictor of SSB consumption in childhood $^{(35)}$. Park and colleagues, in their analysis of 1333 US children, reported that a child's SSB intake during infancy significantly increased the likelihood of SSB consumption at age 6 years ${ }^{(35)}$. The consequences of SSB intake during very early childhood on later childhood have also been reported. For example, Pan and colleagues reported that obesity in childhood (at age 6 years) was $71 \%$ higher in children who consumed SSB during infancy ${ }^{(36)}$. Additionally, a review by Zheng and colleagues described an association between SSB substitution with alternative beverages (milk and low-energy beverages) and long-term lower weight gain in children and adolescents between 8 and 18 years of age ${ }^{(37)}$. Coupled with the longitudinal relationships reported in both the Park and Pan studies, our findings suggest that fathers may provide a possible avenue for intervention with respect to SSB intake in childhood. For example, interventions could include a focus on reducing fathers' SSB intake prior to the establishment of early childhood dietary intakes. Additionally, in the case of children of primary-school age, interventions could focus on replacing fathers' SSB intake with suitable, lowerenergy beverages such as water.

Our observation of cross-sectional associations between fathers' and children's sweet snack intakes at child age 20 months and 5 years is of concern. Also of concern is fathers' sweet snack intake at child age 20 months influencing the increase in children's sweet snack intake between the age of 20 months and both 3.5 years and 5 years. Importantly, the influence of the change to 3.5 years was independent of mothers' intake. It is thought that rapid weight gain in early childhood is an important contributor to childhood weight status ${ }^{(38)}$ and subsequent child/adolescent health ${ }^{(39)}$. In their longitudinal study of over 230 UK children, Gardner and colleagues measured the weight of participants at birth and at 5 and 9 years of age. They found that most prepubertal weight gain occurs prior to the age of 5 years ${ }^{(38)}$. Coupled with the established high intakes of nutrient-poor, energy-dense foods in children $^{(1,2)}$ and the accumulating evidence that the dietary behaviours of young children impact health consequences in later life ${ }^{(5)}$, our findings suggest that fathers may have an independent impact on this key source of energy-dense snacks during early childhood and that interventions aimed at influencing the establishment of young children's dietary behaviours involving fathers are warranted.

Our investigation was novel in its focus on fathers and young children's dietary relationships. Study strengths were the inclusion of both cross-sectional and longitudinal data, the sampling of fathers across all socio-economic categories, adjustment for maternal intake and the use of 
three $24 \mathrm{~h}$ dietary recalls, which is considered the bestpractice diet data collection method for children. There were some limitations to the study that should also be noted. The number of participants lost to follow-up may have impacted the strength of the current findings. While the characteristics of fathers across all time points remained relatively stable, a larger proportion of participants with a higher education level (at child age 20 months) were retained at child age 5 years, which may limit generalizability. Additionally, while a larger proportion of Australian-born participants were lost to follow-up at child age 5 years, the sample was still majority Australian-born, thus limiting generalizability across different cultures. The sample size may have also limited the sex-specific analysis. Dietary data were self-reported for fathers and proxy-reported for children (by mothers) and may be susceptible to social desirability bias. However, since the focus of the study is the relationship between father and child data, these relationships should still be apparent even in the presence of a biased data collection method such as an FFQ. A potential further limitation relates to the generalizability of these findings involving first-born children to associations between fathers and their subsequent children.

\section{Conclusion}

Our results show associations between fathers' and children's fruit and sweet snack intakes at 20 months and 5 years of age. Our results also demonstrate clear associations between fathers' intakes of SSB and sweet snacks and change in infant SSB and sweet snack consumption between 20 months and both 3.5 and 5 years of age. These associations were only mildly attenuated after adjustment for mothers' intake, suggesting an independent effect of fathers' diet on consumption of these foods by their children. This is, to our knowledge, the first time this has been reported in father-child dyads involving children under 5 years of age and adds to the limited literature on the relationship between the diets of children and their fathers. The associations observed in our study demonstrate the potential importance of including fathers in interventions that aim to influence the development of children's diets.

\section{Acknowledgements}

Financial support: This work was supported by the National Health and Medical Research Council (NHMRC; grant numbers 425801 and 1008879). A.J.C. is supported by an NHMRC post-doctoral training fellowship (1013313) and the NHMRC Centre for Research Excellence in Obesity Policy and Food Systems (1041020); K.D.H. is supported by an Australian Research Council Future Fellowship
(FT130100637) and an Honorary National Heart Foundation of Australia Future Leader Fellowship (100370); A.D.W., D.C. and K.J.C. have no financial relationships relevant to this article to disclose. The organizations providing financial support had no role in the design, analysis or writing of this article. Conflict of interest: None. Authorship: A.D.W. drafted and edited the manuscript, conducted statistical analyses, contributed to the interpretation of the results and had primary responsibility for the final manuscript as submitted. A.J.C. advised on the statistical analyses, contributed to the interpretation of the results and reviewed the manuscript. D.C. was a co-investigator on the on the Melbourne InFANT Program, contributed to the interpretation of the results and reviewed the manuscript. K.D.H. designed and co-led the Melbourne InFANT Program, contributed to the interpretation of the results and reviewed the manuscript. K.J.C. was the principal investigator on the Melbourne InFANT Program. She designed and co-led that study, managed the dietary data collection, contributed to the interpretation of the results and reviewed the manuscript. All authors approved the final manuscript as submitted. Ethics of human subject participation: The Melbourne InFANT Program was approved by the Deakin University Human Research Ethics Committee and the Victorian Government Department of Human Services, Office for Children, Research Coordinating Committee. All participants provided informed written consent.

\section{References}

1. Commonwealth of Australia (2008) 2007 Australian National Children's Nutrition and Physical Activity Survey: Main Findings. Canberra: Commonwealth of Australia.

2. Emmett P (2009) Dietary assessment in the Avon Longitudinal Study of Parents and Children. Eur J Clin Nutr 63, Suppl. 1, S38-S44.

3. Siega-Riz AM, Deming DM, Reidy KC et al. (2010) Food consumption patterns of infants and toddlers: where are we now? J Am Diet Assoc 110, 12 Suppl., S38-S51.

4. Cowin I \& Emmett P (2007) Diet in a group of 18-month-old children in South West England, and comparison with the results of a national survey. J Hum Nutr Diet 20, 254-267.

5. Reilly JJ \& Kelly J (2011) Long-term impact of overweight and obesity in childhood and adolescence on morbidity and premature mortality in adulthood: systematic review. Int J Obes (Lond) 35, 891-898.

6. Campbell K \& Crawford D (2001) Family food environments as determinants of preschool-aged children's eating behaviours: implications for obesity prevention policy. A review. Aust J Nutr Diet 58, 19-25.

7. Berge JM, Wall M, Neumark-Sztainer D et al. (2010) Parenting style and family meals: cross-sectional and 5-year longitudinal associations. J Am Diet Assoc 110, 1036-1042.

8. Birch LL (1980) Effects of peer model's food choices and eating behaviors on preschoolers' food preferences. Child Dev 51, 489-496.

9. Birch LL \& Fisher JO (1998) Development of eating behaviours among children and adolescents. Pediatrics 101, 539-549. 
10. Skinner JD, Carruth BR, Bounds W et al. (2002) Children's food preferences: a longitudinal analysis. J Am Diet Assoc 102, 1638-1647.

11. Cooke LJ, Wardle J, Gibson EL et al. (2004) Demographic, familial and trait predictors of fruit and vegetable consumption by pre-school children. Public Health Nutr $\mathbf{7}$, 295-302.

12. Carnell S, Cooke L, Cheng R et al. (2011) Parental feeding behaviours and motivations. A qualitative study in mothers of UK pre-schoolers. Appetite 57, 665-673.

13. Wang Y, Beydoun MA, Li J et al. (2011) Do children and their parents eat a similar diet? Resemblance in child and parental dietary intake: systematic review and metaanalysis. J Epidemiol Community Health 65, 177-189.

14. Peters J, Sinn N, Campbell K et al. (2011) Parental influences on the diets of 2-5-year-old children: systematic review of interventions. Early Child Dev Care 182, 837-857.

15. Rasmussen M, Krølner R, Klepp K-I et al. (2006) Determinants of fruit and vegetable consumption among children and adolescents: a review of the literature. Part I: quantitative studies. Int J Behav Nutr Phys Act 3, 22.

16. Sotos-Prieto M, Santos-Beneit G, Pocock S et al. (2015) Parental and self-reported dietary and physical activity habits in pre-school children and their socio-economic determinants. Public Health Nutr 18, 275-285.

17. Beydoun MA \& Wang Y (2009) Parent-child dietary intake resemblance in the United States: evidence from a large representative survey. Soc Sci Med 68, 2137-2144.

18. Harris TS \& Ramsey M (2015) Paternal modeling, household availability, and paternal intake as predictors of fruit, vegetable, and sweetened beverage consumption among African American children. Appetite 85, 171-177.

19. Robinson LN, Rollo ME, Watson J et al. (2014) Relationships between dietary intakes of children and their parents: a cross-sectional, secondary analysis of families participating in the Family Diet Quality Study. J Hum Nutr Diet 28, 443-451.

20. Hall L, Collins CE, Morgan PJ et al. (2011) Children's intake of fruit and selected energy-dense nutrient-poor foods is associated with fathers' intake. J Am Diet Assoc 111, 1039-1044.

21. Campbell K, Hesketh K, Crawford D et al. (2008) The Infant Feeding Activity and Nutrition Trial (INFANT) an early intervention to prevent childhood obesity: clusterrandomised controlled trial. BMC Public Health 8, 103.

22. Campbell KJ, Lioret S, McNaughton SA et al. (2013) A parent-focused intervention to reduce infant obesity risk behaviors: a randomized trial. Pediatrics 131, 652-660.

23. Hodge A, Patterson AJ, Brown WJ et al. (2000) The Anti Cancer Council of Victoria FFQ: relative validity of nutrient intakes compared with weighed food records in young to middle-aged women in a study of iron supplementation. Aust N Z J Public Health 24, 576-583.

24. Ireland P, Jolley D, Giles G et al. (1994) Development of the Melbourne FFQ: a food frequency questionnaire for use in an Australian prospective study involving an ethnically diverse cohort. Asia Pac J Clin Nutr 3, 19-31.

25. Blanton CA, Moshfegh AJ, Baer DJ et al. (2006) The USDA Automated Multiple-Pass Method accurately estimates group total energy and nutrient intake. $J$ Nutr 136, 2594-2599.

26. Spence AC, McNaughton SA, Lioret S et al. (2013) A health promotion intervention can affect diet quality in early childhood. J Nutr 143, 1672-1678.

27. Department of Health and Ageing (2007) 2007 Australian National Children's Nutrition and Physical Activity Survey: User Guide. Canberra: Department of Health and Ageing.

28. Twisk JW (2013) Applied Longitudinal Data Analysis for Epidemiology. A Practical Guide. Cambridge: Cambridge University Press.

29. Walsh A, Cameron A, Hesketh K et al. (2015) Associations between dietary intakes of first-time fathers and their 20-month-old children are moderated by fathers' BMI, education and age. BrJ Nutr 114, 988-994.

30. Chatterjee S \& Hadi AS (1986) Influential observations, high leverage points, and outliers in linear regression. Stat Sci $\mathbf{1}$, 379-393.

31. Longbottom PJ, Wrieden WL \& Pine CM (2002) Is there a relationship between the food intakes of Scottish $51 / 2-81 / 2$-year-olds and those of their mothers? J Hum Nutr Diet 15, 271-279.

32. Lioret S, McNaughton SA, Crawford D et al. (2012) Parents' dietary patterns are significantly correlated: findings from the Melbourne Infant Feeding Activity and Nutrition Trial Program. Br J Nutr 108, 518-526.

33. Elfhag K, Tynelius P \& Rasmussen F (2010) Family links of eating behaviour in normal weight and overweight children. Int J Pediatr Obes 5, 491-500.

34. Hearn MD, Baranowski T, Baranowski J et al. (1998) Environmental influences on dietary behavior among children: availability and accessibility of fruits and vegetables enable consumption. J Health Educ 29, 26-32.

35. Park S, Pan L, Sherry B et al. (2014) The association of sugar-sweetened beverage intake during infancy with sugar-sweetened beverage intake at 6 years of age. Pediatrics 134, Suppl. 1, S56-S62.

36. Pan L, Li R, Park S et al. (2014) A longitudinal analysis of sugar-sweetened beverage intake in infancy and obesity at 6 years. Pediatrics 134, Suppl. 1, S29-S35.

37. Zheng M, Allman-Farinelli M, Heitmann BL et al. (2015) Substitution of sugar-sweetened beverages with other beverage alternatives: a review of long-term health outcomes. J Acad Nutr Diet 115, 767-779.

38. Gardner DS, Hosking J, Metcalf BS et al. (2009) Contribution of early weight gain to childhood overweight and metabolic health: a longitudinal study (EarlyBird 36). Pediatrics 123, e67-e73.

39. Ekelund U, Ong KK, Linne Y et al. (2007) Association of weight gain in infancy and early childhood with metabolic risk in young adults. J Clin Endocrinol Metab 92, 98-103. 